\title{
Evaluation of the presence of cereulide in food products collected from the Belgian market
}

\author{
Karolien Witpas ${ }^{*}$ (D) Joris Van Loco, Nadine Botteldoorn and Mirjana Andjelkovic
}

\begin{abstract}
Background: Certain strains of Bacillus cereus can produce the emetic toxin cereulide, which is known to cause acute food poisoning. Cereulide, however, also has the potential to cause chronic toxicity due to repeat sub-emetic exposure to the toxin. In this study the presence of B. cereus and cereulide in food stuffs from the Refrigerated Processed Foods of Extended Durability group, containing either pasta or rice, collected from the Belgian market was assessed, in order to evaluate the routes by which contamination with cereulide can occur and verify the presence or absence of the toxin in sub-emetic doses.
\end{abstract}

Findings: The results showed that only a small portion of the samples contained a very low total count of $B$. cereus, too low to cause illness, the other samples were negative.

Conclusions: Cereulide was not detected in any of the collected samples, which supports the theory that contamination most likely occurs due to improper storage and unhygienic conditions.

Keywords: Cereulide, Emetic toxin, Bacillus cereus, LC-MS/MS, Foodborne disease, Food samples, Ready-to-eat foods

\section{Findings}

In this study the presence and prevalence of cereulide (preformed toxin produced by certain strains of spore forming B. cereus) was assessed in three types of Refrigerated Processed Foods of Extended Durability (REPFED), ready-to-heat (RTH) and ready-to-reheat (RTR) food products in order to evaluate the safety of these food products produced by Belgian food industry (Daeleman et al. 2013).

Since $B$. cereus grows best in a starch-rich environment (Samapundo et al. 2011), a total of 84 samples of fresh and frozen RTH lasagne $(n=34)$, RTH pizza $(n=13)$, RTR rice dishes $(n=22)$ and RTE rice cakes $(n=15)$ were collected from Belgian supermarkets, deli-shops and bakeries in the province of Flemish Brabant and the Brussels Capitol Region. After collection, the samples were brought to the lab by means of refrigerated transport within a timeframe of $\max 2 \mathrm{~h}$. There, all samples were homogenized. The microbiological enumeration was performed immediately after sampling, the samples for chemical analysis were stored in the freezer until the time of analysis.

* Correspondence: Karolien.Witpas@wiv-isp.be

Scientific Institute of Public Health, Juliette Wytsmanstraat 14, B-1050 Brussels, Belgium

\section{Springer}

(c) 2015 Witpas et al. Open Access This article is distributed under the terms of the Creative Commons Attribution 4.0 International License (http://creativecommons.org/licenses/by/4.0/), which permits unrestricted use, distribution, and reproduction in any medium, provided you give appropriate credit to the original author(s) and the source, provide a link to the Creative Commons license, and indicate if changes were made.
For the enumeration of B. cereus, the ISO7932 method was used, where the samples were plated on mannitol egg yolk polymyxin (MYP) medium and then incubated for $24-48 \mathrm{~h}$ at $30{ }^{\circ} \mathrm{C}$. Afterwards a PCR was performed on the formed colonies to confirm the presence of cereulide ces gene, responsible for encoding cereulide biosynthetase, following the ISO22174 method. PCR was performed using a GeneAmp ${ }^{\circ}$ PCR System 9700 Thermocycler (Applied biosystems). To prepare the PCR-mixture, each colony was suspended in DNase free water, which was subsequently heated, centrifuged and iced. The B. cereus reference strain BC Kinrooi 5958C (TIAC489) was used as a positive control for the lysis reaction. Cross contamination was detected by means of a negative control where water is added to the PCRmixture instead of DNA.

To assess the presence and prevalence of cereulide, Ultra Performance Liquid Chromatography followed by tandem Mass Spectrometry (UPLC-MS/MS) (Waters Xevo TQ-S) was performed. Cereulide was extracted from the sample using acetonitrile with addition of synthetic ${ }^{13} \mathrm{C}_{6}$-cereulide as an internal standard (DIS-ISO 18465). All UPLC-MS/MS analyses were performed using a triple quadropole UPLC-ESI-MS/MS and an Acquity BEH C18 $50 \mathrm{~mm} \times 2.1 \mathrm{~mm} \times 1.7 \mu \mathrm{m}$ column, 
both from Waters (USA). For detection of cereulide and ${ }^{13} \mathrm{C}_{6}$-labeled cereulide, the $\mathrm{m} / \mathrm{z}$ values of respectively 1170.5 and 1176.5 ( $\mathrm{NH}^{4+}$ adducts) were chosen for the mother ions. For the $\mathrm{m} / \mathrm{z}$ values of the daughter ions, 314.2 and 499.3 were chosen for cereulide and 172.3 for the ${ }^{13} \mathrm{C}_{6}$-labeled cereulide. For the ionization parameters, capillary voltage was set to $3 \mathrm{kV}$, cone voltage to $60 \mathrm{~V}$, source temperature to $150{ }^{\circ} \mathrm{C}$, desolvation temperature to $550{ }^{\circ} \mathrm{C}$, cone gas flow to $150 \mathrm{~L} / \mathrm{h}$, desolvation gas flow to $1200 \mathrm{~L} / \mathrm{h}$, collision gas flow to $0.17 \mathrm{~mL} / \mathrm{min}$ and the collision gas pressure to 7.69 .10 ${ }^{-5}$ mbar. All samples were analysed in ESI+ mode and the LOQ was set at $0.31 \mathrm{ng} / \mathrm{g}$. The recovery of the method was determined by means of a control sample spiked with synthetic cereulide standard with a concentration of $28.89 \mathrm{ng} / \mathrm{g}$. The mean recoveries were $86.48 \%$ for foods containing rice and $91.1 \%$ for foods containing pasta in the overall range from 79.3 to $96.2 \%$. These values comply with the acceptance limits determined in the European Commission decision 2002/657/EC.

Cereulide presence was evaluated at two time points: directly after sampling and after a period of 5-day exposure to a temperature of $25{ }^{\circ} \mathrm{C}$ to mimic abuse conditions, complementary to the previous study of Delbrassinne et al. (2012) and taking into account the B. cereus optimal growth conditions (Delbrassinne et al. 2011).

The results showed that no traces of cereulide were present in the collected samples, neither before nor after 5 day incubation at $25^{\circ} \mathrm{C}$.

Microbiological enumeration was only performed directly after sampling and not after exposure to the abuse conditions. These results showed that $29.8 \%$ of the samples contained B. cereus, with none of the samples exceeding $500 \mathrm{CFU} / \mathrm{g}$ (Table 1). The complementary PCRanalysis showed no presence of the ces gene, which in turn confirms the abovementioned negative UPLC-MS/ MS analysis results. The number of colonies that was detected, is at least 2000 times lower than the threshold of what is considered safe for consumption (EFSA 2005). This implies that none of the collected samples might cause a food intoxication, as long as it is consumed before the expiration date and stored properly. The highest $\mathrm{CFU} / \mathrm{g}$ was found in the rice dishes. This can possibly be explained by the study of Samapundo et al. (2011), which suggests that $B$. cereus might grow better in rice.
This study supports the theory that rice is a high risk food for $B$. cereus prevalence. The main conclusion, however, is that the prevalence of B.cereus and cereulide is most likely caused by improper storage and/or food preparation under unhygienic conditions then resulting from industrial production processes. This low prevalence of $B$. cereus and the absence of cereulide can most likely be attributed to good manufacturing practice and an adequate food security monitoring system in the industry. Preventive approaches, such as the hazard analysis and critical control points (HACCP) system, are adequate to monitor the presence of $B$. cereus in the production process. This is not necessarily directly applicable for cereulide, since it is preformed by the bacteria and highly resistant to heat andcan survive any heat treatment used in the food industry (Rajkovic et al. 2008). Therefore, it is prudent to continue with routine testing of the market, even though no cereulide was detected in this study.

In 2013, a total of 23 verified outbreaks of food poisoning occurred in Belgium, one of the main causative agents of these outbreaks was enterotoxin-producing Bacillus cereus (EFSA 2013). Nevertheless, besides production of cereulide and inducing the emetic syndrome some other strains of $B$. cereus may be responsible for diarrhoeal syndrome (Agata et al. 1995; Melling et al. 1976). It is generally assumed that food containing doses $<10^{5}-10^{6} \mathrm{CFU} / \mathrm{g}$ of $\mathrm{B}$. cereus and $<8 \mu \mathrm{g}$ cereulide $/ \mathrm{kg}$ bodyweight is safe for consumption and will not cause acute intoxication (Rajkovic 2014). Another potential threat, however, lies in repeat sub-emetic exposure to the toxin (Rajkovic 2014; Rajkovic et al. 2014; Vangoitsenhoven et al. 2014). It has already been demonstrated that restaurants pose a potential source of these kinds of exposure, most likely caused by poor storage conditions or inappropriate handling of the food (Delbrassinne et al. 2012; Thorsen et al. 2009). However, since to this date there is no legislation concerning the maximum levels of cereulide in food, the food industry does not control the parameter on a regular bases and may unintentionally contribute to a risk. This concern specifically rises for REPFED food products, due to the greater likeliness of bacterial spores surviving the mild heating process (Samapundo et al. 2011).

Table 1 Results of the enumeration of B. cereus

\begin{tabular}{lllllll}
\hline & No B. cereus detected & $<10$ CFU/g & $10-50$ CFU/g & $50-100$ CFU/g & $100-500$ CFU/g & $>500$ CFU/g \\
\hline Lasagne $(n=34)$ & $27(79.4 \%)$ & $7(20.6 \%)$ & - & - & - & - \\
Pizza $(n=13)$ & $6(46.2 \%)$ & $7(53.8 \%)$ & - & - & $4(18.2 \%)$ \\
Rice dishes $(n=22)$ & $12(54.5 \%)$ & $1(4.5 \%)$ & $4(18.2 \%)$ & $1(4.5 \%)$ & - \\
Rice cakes $(n=15)$ & $14(93.3 \%)$ & - & $1(6.7 \%)$ & - & - \\
\hline
\end{tabular}


In addition to this, further research is necessary to assess possible exposure routes of cereulide. These should include a more thorough sampling of restaurants, the systematic analysis of food intoxication samples and an evaluation of the level of cereulide contamination during household food preparation and preservation. This is necessary because the fact remains that repeat exposure to incorrectly prepared food which contains low levels of cereulide, as can be found in some restaurants (Delbrassinne et al. 2012) or in the homekitchen (Røssvoll et al. 2014), can be potentially harmful since cereulide may lead to cell apoptosis (Vangoitsenhoven et al. 2014).

\section{Competing interests}

The authors declare that they have no competing interests.

\section{Authors' contributions}

KW carried out the collection of the samples, the LC-MS/MS-analysis and the interpretation of the results and drafted the manuscript. ND coordinated the bacteriological analysis. MA and JVL conceived the study, and participated in its design and helped to draft the manuscript. All authors read and approved the final manuscript.

Received: 19 August 2015 Accepted: 4 November 2015

Published online: 09 November 2015

\section{References}

Agata N, Ohta M, Mori M, Isobe M. A novel dodecadepsipeptide, cereulide, is an emetic toxin of Bacillus cereus. FEMS Microbiol Lett. 1995;129(1):17-9.

Daeleman J, Jacxsens L, Devlieghere F, Uyttendaele M. Microbial safety and quality of various types of cooked chilled foods. Food Control. 2013;30:510-7.

Delbrassinne L, Andjelkovic M, Rajkovic A, Botteldoorn N, Mahillon J, Van Loco J. Follow-up of the Bacillus cereus emetic toxin production in penne pasta under household conditions using liquid chromatography coupled with mass spectrometry. Food Microbiol. 2011;28:1105-9.

Delbrassinne L, Andjelkovic M, Dierick K, Denayer S, Mahillon J, Van Loco J. Prevalence and levels of Bacillus cereus emetic toxin in rice dishes randomly collected from restaurants and comparison with the levels measured in a recent foodborne outbreak. Foodborne Pathog Dis. 2012;9:809-14.

EFSA. Opinion of the scientific panel on biological hazards on Bacillus cereus and other Bacillus spp in foodstuffs. EFSA J. 2005;175:1-48.

EFSA. Trends and sources of zoonoses and zoonotic agents in humans, foodstuffs, animals and feedingstuffs. Belgium - 2013 report on trends and sources of zoonoses. 2013

Melling J, Capel BJ, Turnbull PCB, Gilbert RJ. Identification of a novel enterotoxigenic activity associated with Bacillus cereus. J Clin Pathol. 1976;29:938-40.

Rajkovic A. Microbial toxins and low level of foodborne exposure. Trends Food Sci Technol. 2014:38:149-57.

Rajkovic A, Uyttendaele M, Vermeulen A, Andjelkovic M, Fitz-Fames I, in't Veld P, et al. Heat resistance of Bacillus cereus emetic toxin, cereulide. Lett Appl Microbiol. 2008;46(5):536-41.

Rajkovic A, Grootaert C, Butorac A, Cucu T, De Meulenaer B, van Camp J, et al. Sub-emetic toxicity of Bacillus cereus toxin cereulide on cultured human enterocyte-like Caco-2 cells. Toxins. 2014;6:2270-90.

Røssvoll E, Thorsen Rønning H, Einar Granum P, Møretrø T, Røine Hjerpekjøn M, Langsrud S. Toxin production and growth of pathogens subjected to temperature fluctuations simulating consumer handling of cold cuts. Int J Food Microbiol. 2014;185:82-92.

Samapundo S, Heyndrickx M, Xhaferi R, Devlieghere F. Incidence, diversity and toxin gene characteristics of Bacillus cereus group strains isolated from food products marketed in Belgium. Int J Food Microbiol. 2011;150(1):34-41.

Thorsen L, Bjørn Budde B, Henrichsen L, Martinussen T, Jakobsen M. Cereulide formation by Bacillus weihenstephanensis and mesophilic emetic Bacillus cereus at temperature abuse depends on pre-incubation conditions. Int J Food Microbiol. 2009;134:133-9.

Vangoitsenhoven R, Rondas D, Crèvecoeur I, D'Hertog W, Baatsen P, Masini M, et al. Foodborne cereulide causes beta-cell dysfunction and apoptosis. PLoS One. 2014;9(8):e104866. doi:10.1371/journal.pone.0104866.

\section{Submit your manuscript to a SpringerOpen ${ }^{\odot}$ journal and benefit from:}

- Convenient online submission

- Rigorous peer review

- Immediate publication on acceptance

- Open access: articles freely available online

- High visibility within the field

- Retaining the copyright to your article

Submit your next manuscript at $>$ springeropen.com 